\title{
Medication errors in anaesthetic practice: a report of two cases and review of the literature
}

\author{
*Ogboli-Nwasor E
}

Department of Anaesthesia, Ahmadu Bello University Teaching Hospital, Zaria, Nigeria

\begin{abstract}
Background: Mistakes in the identification and administration of drugs may be fatal. This is especially so in the practice of anaesthesia. This is a report of 2 cases of near fatality due to mistakes in drug administration from look-alike medications. Objective: To highlight the significance of medication errors in our practice and to discuss the best methods of prevention. Method: A report of two cases of errors in the administration of drugs during the conduct of anaesthesia. The subsequent management of the cases is presented, and the findings from the literature are discussed.

Result: In case 1, an adult male presented for herniorrhaphy and after induction with propofol $1 \mathrm{mg} / \mathrm{kg}$ intravenously, Pancuronium bromide injection $4 \mathrm{mg}$ was administered intravenously, in the place of suxamethonium chloride injection. In case 2, For induction of anaesthesia, $100 \mathrm{mg}$ of thiopentone sodium was administered in place of $25 \mathrm{mg}$ of the same drug because Thiopentone $1 \mathrm{gm}$ vial was mistaken for Thiopentone $500 \mathrm{mg}$ vial in a 2 year old girl. In both cases, the errors were detected early and there were no adverse sequelae.

Conclusion: Medication errors are a potential source of iatrogenic harm to patients undergoing anaesthesia. Strict adherence to principles as well as constant vigilance would minimize this problem.

Key words: Medication errors, anaesthetic practice, vigilance, safety

African Health Sciences 2013; 13(3): 845 - 849 http://dx.doi.org/10.4314/ahs.v13i3.46
\end{abstract}

\section{Case reports}

\section{Case 1}

B.M a 50 year old male farmer presenting with a right inguino-scrotal hernia for herniorrhaphy (RISH). Induction was with propofol $1 \mathrm{mg} / \mathrm{kg}$ intravenously. Endotracheal intubation was to be facilitated by suxamethonium $0.5 \mathrm{mg} / \mathrm{kg}$ intravenously but the anaesthesia practitioner who was assisting withdrew pancuronium bromide $4 \mathrm{mg}$ and injected intravenously.

Oxygen was administered by facemask, although after about 90 seconds, fasciculation was not observed the patient was noticed to be well relaxed. Laryngoscopy was done and upon visualization of larynx, a size $7.5 \mathrm{~mm}$ ETT was inserted with ease. The plan was to allow the patient breathe spontaneously and maintain with propofol infusion and $30 \mathrm{mg}$ pentazocine intravenous bolus for analgesia. After about 5 minutes the patient was noticed not to be making any respiratory efforts. Intermittent Positive Pressure Ventilation (IPPV) was continued and the attending anaesthetist asked for

*Corresponding author:
Elizabeth Ogboli-Nwasor
Department of Anaesthesia
Ahmadu Bello University Teaching Hospital
Zaria, Nigeria
Email: drnwasor@yahoo.com

the drug ampoule. It was then discovered that pancuronium $4 \mathrm{mg}$ ampoule had been mistaken for a suxamethonium $100 \mathrm{mg}$ ampoule! IPPV was maintained throughout the surgery. At the end of surgery, residual paralysis was reversed with neostigmine and atropine and the patient was extubated. He recovered fully with no adverse sequelae (see figure 1).

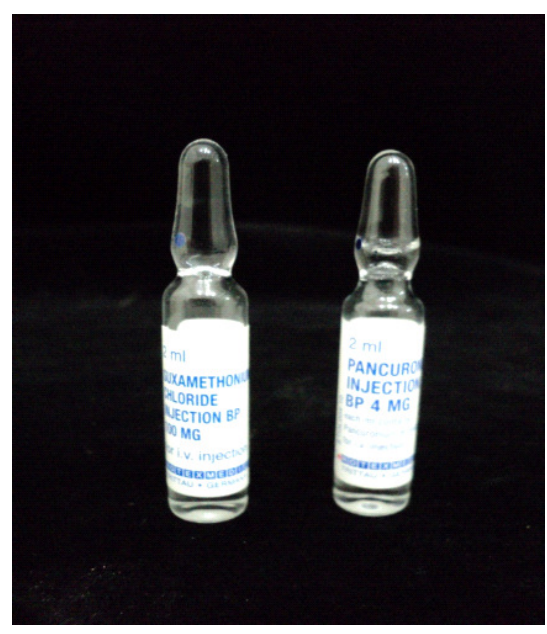

Figure 1: Similar looking ampoules of suxamethonium and pancuronium 


\section{Case 2}

A 2-year old child with Retinoblastoma was booked for enucleation. At induction of anaesthesia $100 \mathrm{mg}$ of thiopentone sodium was administered in place of $25 \mathrm{mg}$ of the same drug! Suxamethonium chloride $12.5 \mathrm{mg}$ I.V was given and the child was intubated with a size $2.5 \mathrm{~mm}$ ETT. It was observed that the ventilation had to be assisted for over 10 minutes before spontaneous respiration was resumed. We were wondering whether there was a prolongation in the effect of suxamethonium. All the drugs drawn were crosschecked only to discover that the anaesthetist had mixed $1 \mathrm{gm}$ of thiopentone with $10 \mathrm{ml}$ and thereafter had withdrawn $1 \mathrm{ml}(100 \mathrm{mg})$ and injected instead of the $25 \mathrm{mg}$ that was supposed to be administered. (See figure 2) IPPV was continued and monitoring, there were no untoward sequelae in both cases.

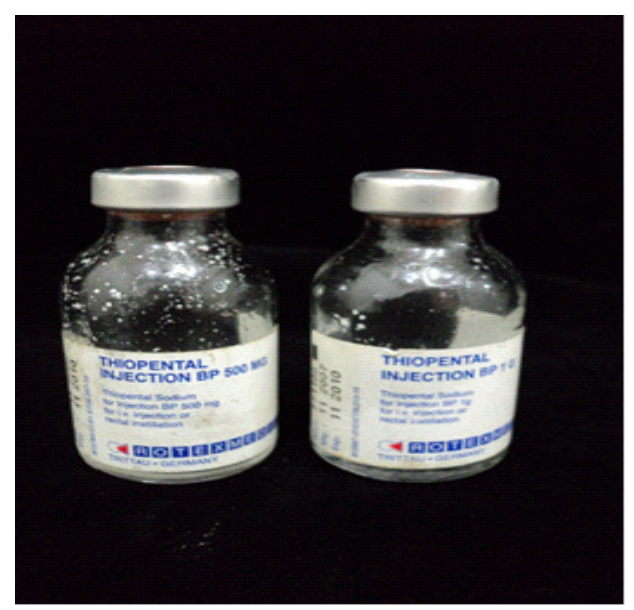

Figure 2: Thiopentone $500 \mathrm{mg}$ and $1 \mathrm{gm}$ vials

\section{Discussion}

While there is relatively little information about drug administration errors made by anaesthesiologists, the available data suggest that anesthesia-related drug administration errors are relatively common. Prospective studies suggest that the error rate in anaesthesia is around one error in every 133 anaesthetics ${ }^{1}$. There is a dearth of information in the West-African sub-region about drug administration errors among anaesthesiologists. Mato and Fyneface-Ogan reported cases of drug administration errors in a Nigerian Teaching Hospital, which was mostly attributed to human error $^{2}$.

Drug administration errors appear to be a major source of iatrogenic harm to hospitalized patients. Medication errors are 846 common throughout healthcare and result in significant human and financial cost. A recent study estimated that drug-related errors occur in one out of five doses given to patients in hospitals ${ }^{3}$. Administration errors were found to account for 38 percent of drug-related errors ${ }^{4}$, and the annual cost of drug-related errors was estimated to be approximately $\$ 2.8$ million for a 700 -bed teaching hospital ${ }^{5}$.

In a survey of anaesthesiologists in New Zealand, 12.5 percent of anesthesiologists responding to the survey reported having harmed patients by a drug administration error ${ }^{7}$. A subsequent prospective study of 7,794 anaesthetic procedures in New Zealand found an overall incidence of drug administration error of 0.75 percent, based upon self-reporting by anaesthesiologists ${ }^{8}$.

In order to obtain additional information about drug administration errors in the anaesthesia care setting, Bowdle ${ }^{9}$ reviewed the cases of drug administration error contained in the ASA Closed Claims Project database. There were 205 drug errors, representing about 4 percent of the total database of 5,803 cases. The proportion of the database composed of drug errors has been roughly constant, standing at 4 percent for the 1980 s and 1990s. ${ }^{9}$

There are several categories of medication errors ranging from slips and lapses to fixation errors and deliberate violations. Similarity in the presentation and packaging of drugs is a major source of mistakes in our practice just as was illustrated in these case reports. The difference in drug appearance between the generic and the brand name product as well as differences in drug appearance between different generic drug manufacturers for the same medication represents another important means by which patients may experience moderate to serious consequences from a medication error ${ }^{2}$.

Webster et $a^{8}{ }^{8}$ classified drug errors in to the following categories:

Omission: drug not given

Repetition: $\quad$ extra dose of an intended drug Substitution: incorrect drug instead of the desired drug; a swap

Insertion: a drug that was not intended to be given at a particular time or at any time Incorrect dose: wrong dose of an intended drug Incorrect route: wrong route of an intended drug 
Other: usually a more complex event not fitting the categories above

In this report, according to Webster's classification of medication errors, case 1 is an example of a substitution while case 2 is an incorrect dose. In 1993 Russell $^{10}$ examined the first 2000 incident reports in the-Australian Incident Monitoring Study (AIMS). There were recommendations aimed at avoiding drug errors. There were 144 incidents related to drugs: 58 syringe drug swaps and, of these, $71 \%$ involved muscle relaxants. This follows manager's " $80 / 20$ rule": which states that $80 \%$ of the adverse events will come from about $20 \%$ of the drugs ${ }^{11}$. Based on their findings, they recommended change in colour coding of syringes by the drug types they contained. In 1993 there were Standards for Drug Labeling in the USA ${ }^{12}$, Canada $^{13}$, and South Africa. The Australian Society of Anaesthetists used the same basic colour scheme as the three existing national standards ${ }^{13}$.

They also added some requirements in the lettering design and on the quality of the label adhesive. They made some recommendations on muscle relaxants: colour identified by a strong red. Simply identifying the relaxant syringes could avoid about $70-80 \%$ of the syringe swap incidents. To lock in the relationship with red and relaxants, it was decided to try to get a red syringe produced. This, it was hoped, might reduce labeling errors and give a clear indication of the relaxant syringe from all angles (see figure 3).

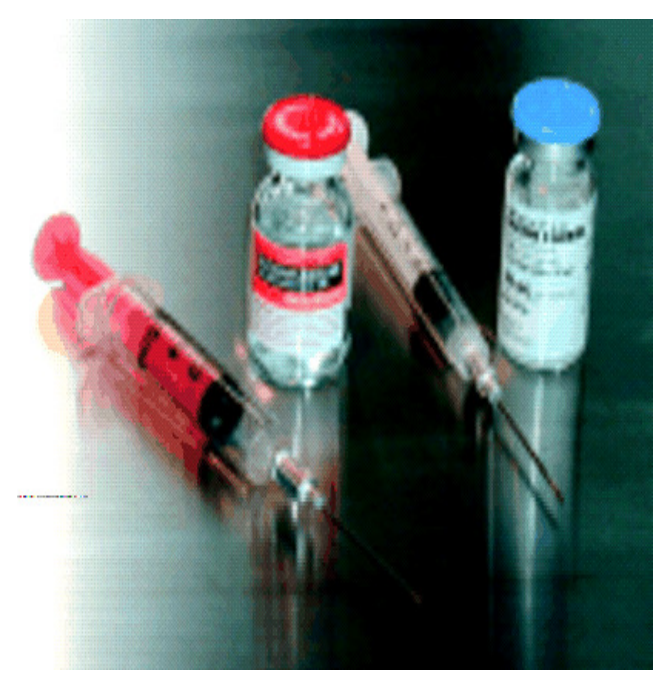

Figure 3: Colour coded vials and syringes
The strategy of identifying the relaxants with the red plunger syringes depends on strictly using the syringe only for relaxants. In spite of this innovation, the problem could not be resolved. Clearly identifying relaxant drugs may help to avoid the very distressing incidents of patients being paralyzed because of a syringe swap before anaesthesia is induced. Although these recommendations are being practiced in some other countries, they are yet to be fully implemented in Sub-Saharan Africa. In another recommended method for minimizing medication errors, all labels are self-adhesive and colored by class of drug, following an international standard (see figure 4).

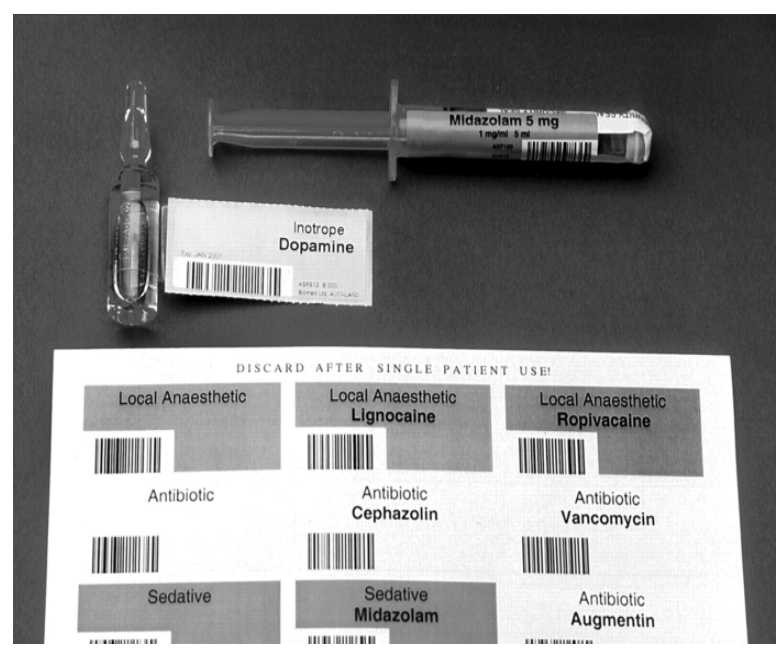

Figure 4: Self-adhesive and colored labels by class of drug, following an international standard

Thus a medication error is an 'error in the prescription, dispensing, or administration of a medication with the result that the patient fails to receive the correct drug or the indicated proper drug dosage' (National Library of Medicine Medical Subject Heading) ${ }^{14}$. It does not necessarily result in injury. There is wide and sometimes interchangeable use of other terms such as 'prescription error', 'drug error', 'dose error', 'adverse drug event (ADE)', 'potential ADE' and 'preventable ADE', used to define the location of the error in the pathway between pharmacy and patient more precisely or indicate that a patient has been harmed ${ }^{14}$.

Medication error rates appear to be higher during day shifts, when the majority of drug orders are made, rather than at night. ${ }^{15,16}$ Inexperience might be expected to contribute towards medication errors, but the published evidence concerns prescription error only. First-year residents are five times more 
likely to make prescribing errors than those with more experience $^{15}$.

There are many hidden problems in the hospital that contribute to systems failure and prescription errors were most likely to cause an ADE. Other latent systems failures include, failure to check drugs before administration, lack of communication, inadequate monitoring of treatment or side-effects, and lack of standardization of labels and protocols. ${ }^{14}$ It is widely quoted that $80 \%$ of medication errors in hospitals are caused by human error, the remainder being due to equipment error. ${ }^{17}$ Previous studies have shown that age, poly pharmacy and impaired renal function ${ }^{14}$ predispose patients to ADEs.

In the index cases reported, the medication errors reported occurred during day shifts and they were both due to human error. There is little information about the epidemiology of medication errors in anaesthetic practice in Sub-Saharan Africa. There is a need therefore to conduct large scale studies to find out the prevalence and incidence of medication errors in anaesthetic practice in SubSaharan Africa. This will be the basis on which regional and national policies guidelines and strategies of prevention of medication errors can be adopted or adapted from other existing guidelines.

\section{Recommendations}

There is a need to study the incidence and prevalence of medication administration errors in anaesthetic practice in Sub-Saharan Africa. The use of international colour coding for syringe labeling and coloured syringes may reduce the occurrence of medication errors. When mistakes do occur the patients should be resuscitated if necessary and investigated properly. Critical incidents should be reported in accordance with laid out guidelines. Drug manufacturing companies and pharmaceuticals should be encouraged to make their labels different and distinct from one another.

\section{Conclusion}

Medication errors can and do occur in anaesthetic practice and are most often attributable to human errors. Similar looking vials and ampoules may be a common factor thus, anaesthetists should be trained to be vigilant at all times during the conduct of an anaesthetic. The watchword for all anaesthetists should be "Eternal vigilance is the price of safety".

\section{References}

1. Glavin R J. Drug errors: consequences, mechanisms, and avoidance British Journal of Anaesthesia 105 (1): 76-82 (2010) Advance Access publication 27 May 2010. doi:10.1093/ $\mathrm{bja} /$ aeq131.

2. Walliser G, Grossberg R, Reed MD. Lookalike medications: a formula for possible morbidity and mortality in the long-term care facility. J Am Med Dir Assoc. 2007 Oct; 8(8):541-2.

3. Barker KN, Flynn EA, Pepper GA, Bates DW, Mikeal RL. Medication errors observed in 36 health care facilities. Arch Intern Med. 2002; 162:1897-1903.

4. Leape LL, Bates DW, Cullen DJ, et al. Systems analysis of adverse drug events. ADE Prevention Study Group. JAMA. 1995; 274:35-43.

5. Bates DW, Spell N, Cullen DJ, et al. The costs of adverse drug events in hospitalized patients. Adverse Drug Events Prevention Study Group. JAMA. 1997; 277:307-311.

6. Mato CN, Fyneface-Ogan S. Drug Errors in Anaesthetic Practice: Case reports. Nig. J. Med 2003; 12(3): 157-9

7. Merry AF, Peck DJ. Anaesthetists, errors in drug administration and the law. N Z Med J 1995; 24:185-187.

8. Webster CS, Merry AF, Larsson L, McGrath $\mathrm{KA}$, Weller J. The frequency and nature of drug administration error during anaesthesia. Anaesth Intensive Care. 2001; 29:494-500.

9. Bowdle, TA: Drug Administration Errors from the ASA Closed Claims Project. ASA Newsletter 2003; 67(6): 11-13

10. Russell WJ. Getting into the red: a strategic step for safety Qual Saf Health Care 2002;11:107 doi:10.1136/qhc.11.1.107

11. Currie M, Mackay P, Morgan C, et al. The "wrong drug" problem in anaesthesia: an analysis of 2000 incident reports. Anaesthesia Intens Care 1993; 21: 596-601

12. American Society for Testing and Materials. Standard specification for user applied drug labels in anesthesiology. American Society for Testing and Materials D4774-94, 1995

13. Canadian Standards Association. Standard for user applied drug labels in anaesthesia and critical care. Z264.3-98. Etobicoke, Canada: Canadian Standards Association, 1998 
14. Wheeler SJ, Wheeler D W. Medication errors in anaesthesia and critical care Anaesthesia. 2005;60: 257-273

15. Lesar TS, Briceland LL, Delcoure K, et al. Medication prescribing errors in a teaching hospital. Journal of the American Medical Association 1990; 263: 2329-34.
16. Raju TN, Kecskes S, Thornton JP, Perry M, Feldman S. Medication errors in neonatal and paediatric intensive-care units. Lancet 1989; 2: 374-6.

17. Dean B, Schachter M, Vincent C, Barber N. Causes of prescribing errors in hospital Inpatients: a prospective study. Lancet 2002; 359: 1373-8. 